TITTLE: SULFATION RATES OF CYCLED CaO PARTICLES IN THE CARBONATOR OF A Ca-LOOPING CYCLE FOR POST-COMBUSTION CO2 CAPTURE

Authors: B. Arias, J. M. Cordero, M. Alonso, J.C. Abanades

Instituto Nacional del Carbón, CSIC, C/ Francisco Pintado Fe, No. 26, 33011, Oviedo, Spain.

*Corresponding author: Dr. Borja Arias

Instituto Nacional del Carbón, C.S.I.C.

C/Francisco Pintado Fe, No26

33011 Oviedo (Spain)

Telephone: +34985119057

Fax: +34985297662

E-mail: borja@incar.csic.es 


\title{
SULFATION RATES OF CYCLED CaO PARTICLES IN THE CARBONATOR OF A Ca-LOOPING CYCLE FOR POST-COMBUSTION $\mathrm{CO}_{2}$ CAPTURE
}

\author{
B. Arias, J. M. Cordero, M. Alonso, J.C. Abanades \\ Instituto Nacional del Carbón, INCAR-CSIC. C/ Francisco Pintado Fe, 26, 33011, Oviedo. Spain \\ borja@incar.csic.es, jmacod@incar.csic.es, mac@incar.csic.es, abanades@incar.csic.es
}

Keywords: sulfation kinetics, $\mathrm{SO}_{2}$ capture, carbonation, $\mathrm{Ca}$ looping, $\mathrm{CO}_{2}$ capture

\begin{abstract}
Calcium looping is an energy-efficient $\mathrm{CO}_{2}$ capture technology that uses $\mathrm{CaO}$ as a regenerable sorbent. One of the advantages of Ca looping compared with other post-combustion technologies is the possibility of operating with flue gases that have a high $\mathrm{SO}_{2}$ content. However, experimental information on sulfation reaction rates of cycled particles in the conditions typical of a carbonator reactor is scarce. This works aims to define a semi-empirical sulfation reaction model at particle level suitable for such reaction conditions. The pore blocking mechanism typically observed during the sulfation reaction of fresh calcined limestones is not observed in the case of highly cycled sorbents $(\mathrm{N}>20)$ and the low values of sulfation conversion characteristic of the sorbent in the Ca-looping system. The random pore model is able to predict reasonably well the $\mathrm{CaO}$ conversion to $\mathrm{CaSO}_{4}$ taking into account the evolution of the pore structure during the calcination/carbonation cycles. The intrinsic reaction parameters derived for chemical and diffusion controlled regimes are in agreement with those found in the literature for sulfation in other systems.
\end{abstract}




\section{Introduction}

Post-combustion $\mathrm{CO}_{2}$ capture using $\mathrm{CaO}$ as a regenerable solid sorbent (or calcium looping, $\mathrm{CaL}$ ) is a rapidly developing technology because of its potential to achieve a substantial reduction in capture cost and because of the energy penalties associated with more mature $\mathrm{CO}_{2}$ capture systems ${ }^{1,2}$. In a post-combustion $\mathrm{CaL}$ system, $\mathrm{CO}_{2}$ from the combustion flue gas of a power plant is captured by using $\mathrm{CaO}$ as sorbent in a circulating fluidized bed (CFB) carbonator operating between $600-700{ }^{\circ} \mathrm{C}$. The stream of partially carbonated solids leaving the carbonator is directed to the CFB calciner, where the solids are calcined, thereby regenerating the sorbent $(\mathrm{CaO})$ and releasing the $\mathrm{CO}_{2}$ captured in the carbonator. In order to calcine the $\mathrm{CaCO}_{3}$ formed in the carbonator and to produce a highly concentrated stream of $\mathrm{CO}_{2}$, coal is burned under oxyfuel conditions at temperatures above $900{ }^{\circ} \mathrm{C}$ in the calciner. One of the main distinctive characteristics of this process is its lower energy penalty, as operation at high temperatures allows for efficient heat integration of the full system in the power plant $t^{3,4,5,6,7,8}$.

Another known benefit of CaL systems compared with other post-combustion technologies, such as amines, is the theoretical capability of operating with flue gases that have a high $\mathrm{SO}_{2}$ content. This is because the calcined limestones present in carbonator and calciner reactors are known to be excellent desulfurization agents, and they are routinely used in many commercial scale power plants, including circulating fluidized bed combustors (see review by 9). Although several recent

works have investigated sulfation phenomena in CaL systems ${ }^{10,11,12,13,14,15,16,17}$, there is very little quantitative information on the sulfation rates of $\mathrm{CaO}$ in the carbonator and calciner reactor environments. 
An important difference between sulfation studies with CFB combustors and sulfation studies with $\mathrm{CaL}$ systems concerns the typical range of conversion to $\mathrm{CaSO}_{4}$ that can be expected of each of these systems. An obvious design target of any commercial flue gas desulfurization process is to make the most use of the $\mathrm{Ca}$ and to achieve maximum conversion to $\mathrm{CaSO}_{4}$. However, in a CaL system, there is generally a need for a large make up flow of low cost limestone to compensate for the decay in the sorbent's $\mathrm{CO}_{2}$ carrying capacity along cycling. A mass balance for the recycling of $\mathrm{Ca}$ solids has shown ${ }^{18}$ that this leads to $\mathrm{CaSO}_{4}$ contents well below $5 \mathrm{~mol} \%$ in a CaL system, even when high sulfur content fuels are used. This has important implications for the debate of the effect of sulfur on CaL systems, because this low conversion of the $\mathrm{Ca}$ sorbent to $\mathrm{CaSO}_{4}$ is well below the limit of conversion required to achieve the extensive pore plugging that is characteristic of highly sulfated particles (see review by Anthony ${ }^{9}$ ). The purpose of this work therefore is to examine more fully the sufation phenomena associated with these low levels of conversion to $\mathrm{CaSO}_{4}$.

Several models have been proposed for studying and describing heterogeneous sulfation reactions and pore plugging processes under different reaction controlled regimes and for different sorbents ${ }^{19,20,21,22,23,24,25}$. The models increase in complexity when they need to quantify the diffusion phenomena of the reactants passing through plugged pores. However, there is a general consensus concerning what happens in the initial stages of the reaction (low sulfation conversions). The first quantitative descriptions of the rate of reaction of $\mathrm{SO}_{2}$ with $\mathrm{CaO}^{26,27}$ established that, in the absence of diffusion through the pores of the particles, the reactivity of the sorbent towards $\mathrm{SO}_{2}$ increases with the internal surface area. The overall reaction rate in these conditions is controlled by the chemical reaction at low values of sulfate conversion and by 
gas diffusion through a layer of $\mathrm{CaSO}_{4}$ formed over the $\mathrm{CaO}$ sorbent that increases as the sulfation conversion increases. Regarding the effect of $\mathrm{SO}_{2}$ concentration in gas phase, there is general agreement the the reaction order ranges from 0.6 to $1^{28,20,22,29}$. This background information should be valuable in modelling the sulfation rates of $\mathrm{CaO}$ particles in the typical conditions of CaL systems.

Another important difference between early works on the sulfation reaction of $\mathrm{CaO}$ in combustion environments and the present study is to do with the range of temperatures. The most suitable mathematical models for describing the rate of sulfation of individual particles are usually fitted to the data obtained at temperatures characteristic of CFBC (around $850{ }^{\circ} \mathrm{C}$ ). However, these conditions differ considerably from those of a carbonator reactor working with a flue gas at lower temperatures $\left(650^{\circ} \mathrm{C}\right)$.

Finally, it is necessary to take into account the special characteristics of the $\mathrm{CaO}$ particles cycling in a $\mathrm{CaL}$ capture system, where the reversible carbonation reaction of $\mathrm{CO}_{2}$ with $\mathrm{CaO}$ has a strong impact on the textural properties of the material. It is well known that the $\mathrm{CO}_{2}$ carrying capacity of $\mathrm{CaO}$ sorbents decays with number of calcinations/carbonations ${ }^{30,31}$ due to a sintering mechanism that drastically reduces the surface with the increasing number of cycles. In a scenario where $\mathrm{SO}_{2}$ is present in the flue gas entering the carbonator reactor, there is additional deactivation of the $\mathrm{CaO}$ sorbent due to the formation of $\mathrm{CaSO}_{4}$. Several works have shown ${ }^{11,12 \text {, }}$ ${ }^{13,17}$ that $\mathrm{SO}_{2}$ accelerates the decrease in $\mathrm{CO}_{2}$ carrying capacity of a sorbent during cycling even when a low ratio of $\mathrm{SO}_{2} / \mathrm{CO}_{2}$ is used. One important conclusion of these cyclic tests is that the performance of limestones may differ considerably during sulfation in contrast to their similar 
behaviour during carbonation ${ }^{13}$. In their studies of the performance of calcium aluminate pellets during co-capture tests of $\mathrm{CO}_{2}$ and $\mathrm{SO}_{2}$ Manovic et al. showed that the deactivation of synthetic sorbents (calcium aluminate pellets) is greater than that of natural limestone sorbent due to their higher reactivity towards $\mathrm{SO}_{2}{ }^{17}$.

On the other hand, the sintering process of $\mathrm{CaO}$ under cyclic carbonation calcination cycles can have a positive impact on sorbent utilization during sulfation. Some researchers have found that the sulfation behaviour of $\mathrm{CaO}$ is enhanced (higher maximum sulfation conversions are achieved) during the calcination/carbonation cycles ${ }^{10,13,14}$. This is because the sintering of the particles during carbonation-calcination is accompanied by a widening of the pores to diameters of several 100s nm after extended (100) cycles $^{32}$. The opened structures formed during the calcination/carbonation cycles are then able to accommodate the bulky product layer of $\mathrm{CaSO}_{4}$, thus reducing the pore blocking mechanism which limits $\mathrm{CaO}$ conversion during sulfation. On the basis of this sorbent behaviour, some researchers have suggested the idea of using the spent sorbent from carbonate looping as feedstock material for $\mathrm{SO}_{2}$ retention in CFB boilers during coal combustion ${ }^{13,15,16}$. This may be one of the reasons why most of the published data on the sulfation of spent sorbents is related with high temperatures typical of combustion temperatures $\left(850-900{ }^{\circ} \mathrm{C}\right)$ and there is lack of experimental information on sulfation rates under carbonation temperatures $\left(650^{\circ} \mathrm{C}\right)$.

The focus in this work is on the capture of $\mathrm{SO}_{2}$ from the flue gas fed into the carbonator reactor, as this operates in conditions that may need to reconsider and reformulate the application of existing models at particle level to describe the sulfation reaction rates of $\mathrm{CaO}$. Indeed, despite 
the large body of literature on the reaction of $\mathrm{CaO}$ with $\mathrm{SO}_{2}$ in a wide range of conditions relevant to the operation of $\mathrm{CFBCs}$, there is insufficient experimental information on sulfation reaction rates in the conditions characteristic of a carbonator reactor (i.e. particles that have undergone very different numbers of carbonation-calcination cycles, having substantially different textural properties and with expected conversions to $\mathrm{CaSO}_{4}$ compared to that of $\mathrm{CFBC}$ systems). This work addresses this knowledge gap and presents what we believe to be the first results of an investigation to define a semi-empirical sulfation reaction model at particle level suitable for the conditions characteristic of a carbonator reactor in a Ca-looping postcombustion system.

\section{EXPERIMENTAL}

Three different limestones with particle sizes in the range of $63-100 \mu \mathrm{m}$ were used for this study. Their chemical composition is shown in Table 1. The calcination/carbonation cycling and the sulfation of the sorbents was experimentally studied using a TGA analyzer especially designed for carrying out long calcination-carbonation cycles, as described elsewhere ${ }^{33}$. This TG consists of a quartz tube installed in a two-zone furnace which is able to work at two different temperatures. The furnace can be moved up or down by means of a pneumatic piston and its position with respect to the sample allows a rapid change from calcination $\left(950{ }^{\circ} \mathrm{C}\right)$ to carbonation temperatures $\left(650^{\circ} \mathrm{C}\right)$ and viceversa. The system is equipped with a microbalance that continuously measures the weight of the sample which is held in a platinum basket. The gas mixture (air/ $/ \mathrm{CO}_{2} / \mathrm{SO}_{2}$ ) was prepared using mass flow controllers and was fed into the bottom of the quartz tube. The weight and temperature of the sample were continuously recorded on a computer. 
The experimental procedure starts with the calcination carbonation cycling of the limestone for a certain number of cycles. During these tests, calcination was carried out in air at $950{ }^{\circ} \mathrm{C}$ and carbonation under $10 \% \mathrm{CO}_{2}$ in air at $650{ }^{\circ} \mathrm{C}$. After cycling, the sample temperature was allowed to stabilize for 10 minutes until a temperature of $650{ }^{\circ} \mathrm{C}$ was reached. A mixture of $\mathrm{SO}_{2}$ with air was then introduced into the quartz tube in order to begin sulfation. Tests were carried out to establish the experimental conditions (sample mass and total gas flow) needed to avoid external diffusion effects. In the light of the results, the total volumetric flux was finally set to $2.25 \times 10-5$ $\mathrm{m}^{3} / \mathrm{s}$, (corresponding to $0.05 \mathrm{~m} / \mathrm{s}$ at $650{ }^{\circ} \mathrm{C}$ ). It was also established that a sample mass below 3 mg was necessary to eliminate external mass diffusion effects (i.e. at $\mathrm{T}=650{ }^{\circ} \mathrm{C}$ and $500 \mathrm{ppmv}$ of $\mathrm{SO}_{2}$ ). $\mathrm{CaO}$ conversion of the sorbent was calculated from the weight gain assuming that $\mathrm{CaSO}_{4}$ would be the main product of the reaction between $\mathrm{CaO}$ and $\mathrm{SO}_{2}$ under the experimental conditions of this work. After the end of each run, the samples were weighed using a different balance to check the accuracy of the TGA. A good agreement between both series of measurements was obtained in all cases.

Table 1. Chemical composition (\% wt) of limestones used in this work.

\section{RESULTS AND DISCUSSION}

Figure 1a shows the evolution of $\mathrm{CaO}$ conversion to $\mathrm{CaSO}_{4}$ with time for limestones tested after a first calcination at a temperature of $650{ }^{\circ} \mathrm{C}$ using $500 \mathrm{ppmv}$ of $\mathrm{SO}_{2}$. As can be seen, the three sorbents exhibit an initial fast period followed by a second period with a lower reaction rate during which the $\mathrm{X}_{\mathrm{CaSO} 4}$ tends to stabilize to an almost constant value. In the case of the 
Compostilla and Imeco limestones, the sulfation rate of $\mathrm{CaO}$ fell sharply after ten minutes of reaction, to a $\mathrm{X}_{\mathrm{CaSO} 4}$ of 0.16 and 0.19 respectively. The reactivity of the Enguera limestone towards sulfation was much higher, yielding a $\mathrm{X}_{\mathrm{CaSO} 4}$ of 0.35 at the end of the sulfation period. The drastic slowing down of the sulfation process has been reported widely in the literature and is attributed to pore blockage due to the different molar volumes of $\mathrm{CaO}$ and $\mathrm{CaSO}_{4}(16.9$ and $46.0 \mathrm{~cm}^{3} / \mathrm{g}$ respectively $)^{9}$.

Figure $1 \mathrm{~b}$ shows the $\mathrm{CaO}$ conversions to $\mathrm{CaSO}_{4}$ after 50 calcination/carbonation cycles. As can be seen, the evolution of $\mathrm{X}_{\mathrm{CaSO} 4}$ is quite similar for the three sorbents after cycling, despite the different behaviours of the freshly calcined limestones (Figure 1a). This is a clear indication of the strong effect of a large number carbonation-calcination cycles on the pore structure of $\mathrm{CaO}$ particles, irrespective of their origin, as revealed in previous studies on carbonation ${ }^{34}$.

Figure 1. $\mathrm{X}_{\mathrm{CaSO} 4}$ vs time for limestones used in this work after the first calcination (a) and 50 calcination/carbonation cycles (b) $\left(\mathrm{T}=650^{\circ} \mathrm{C}, \mathrm{SO}_{2}\right.$ concentration $\left.=500 \mathrm{ppmv}\right)$.

Certain similarities between Figure $1 \mathrm{a}$ and $1 \mathrm{~b}$ are worth highlighting. On the one hand, the sulfation of the $\mathrm{CaO}$ cycled particles seems to maintain a certain transition (at about $300 \mathrm{~s}$ in these figures) between two stages in the rate of reaction. The fast reaction stage has a less inclined slope compared to the equivalent period in the fresh sorbent (Figure 1a), and this can be attributed to the smaller surface area of the $\mathrm{CaO}$ particles after 50 carbonation-calcination cycles. Furthermore, the reduction in the reaction rate during the second stage is less pronounced in the case of the cycled sorbents (as the solid lines show). Even more interesting is the fact that in 
Figure $1 \mathrm{~b}$ the reaction rate remains almost constant until the very end of the sulfation experiment, in contrast with what one would expect when the pore blockage mechanism is takes place (as in Figure 1a). This behaviour might be expected in view of the evolution of the sorbent surface, with cycling, towards one with a more opened texture and wider pores ${ }^{13,17,32,35}$. A comparison of the experimental data in Figure $1 \mathrm{a}$ and $1 \mathrm{~b}$ shows the importance of taking into account the evolution of sorbent texture during the calcination/carbonation cycles when modeling the sulfation process and determining the rate constants, as will be discussed later on.

Experiments with different particle sizes were carried out to evaluate radial diffusion resistances throughout the pore network of the particles, focusing on the low level of sulfate conversion (fast reaction regions in Figure 1). Figure 2 shows the $\mathrm{CaO}$ conversion to $\mathrm{CaSO}_{4}$ for the freshly calcined and cycled $(\mathrm{N}=20)$ Compostilla limestone of two particle sizes, 63-100 and 400-600 $\mu \mathrm{m}$ respectively. As can be seen, the reaction rates are similar for both sizes. This indicates that the $\mathrm{SO}_{2}$ concentration is constant throughout the particle and that the sulfation rate can be described by means of a homogeneous model for these particle size ranges, common in Calcium looping applications with CFB technology. However, this approach should always be reconsidered when using particles of a larger size in other systems.

To study the effect of $\mathrm{SO}_{2}$ on the sulfation rate of $\mathrm{CaO}$, tests with different concentrations were carried out at a temperature of $650{ }^{\circ} \mathrm{C}$. The effect of the $\mathrm{SO}_{2}$ concentration on $\mathrm{X}_{\mathrm{CaSO} 4}$ in the case Compostilla limestone after the first calcination cycle is shown in Figure 3, where the $\mathrm{SO}_{2}$ concentration ranges from 500 to 3000 ppmv. As can be seen, the $\mathrm{SO}_{2}$ concentration has a 
marked effect on the slope of the initial stage of the sulfation process and on the final conversion of the sorbent after 20 minutes of reaction.

Figure 2. Effect of the particle size on the sulfation of $\mathrm{CaO}$ after the first calcination (empty symbols) and 20 calcination/carbonation cycles (filled symbols) $\left(\mathrm{T}=650 \quad{ }^{\circ} \mathrm{C}, \quad \mathrm{SO}_{2}\right.$ concentration $=500 \mathrm{ppmv})$.

As already mentioned, different reaction orders can been found in the literature depending on the sulfation conditions. To determine the reaction order under the sulfation conditions tested in this work, the maximum sulfation rate $(\Delta \mathrm{X} / \Delta \mathrm{t})$ for the initial period (up to reaction times of $100 \mathrm{~s}$ ) was represented against the $\mathrm{SO}_{2}$ concentration. Figure $3 \mathrm{~b}$ shows the results obtained for the slopes of the curves in the case of the fresh calcined Compostilla limestone. As can be seen, a good linearity is observed indicating a pseudo-first order reaction respect to $\mathrm{SO}_{2}$. Figure 2 shows the results obtained for the other limestones $(\mathrm{N}=1)$ and for the Compostilla limestone after 20 calcination/carbonation cycles confirming the first reaction order.

Figure 3. Effect of $\mathrm{SO}_{2}$ concentration on $\mathrm{X}_{\mathrm{CaSO} 4}$ for the fresh calcined Compostilla limestone $(\mathrm{N}=1)\left(\mathrm{T}=650^{\circ} \mathrm{C}\right)(\mathrm{a})$ and the maximum reaction rate $\mathrm{vs} \mathrm{SO}_{2}$ concentration (b).

The experimental results presented above were interpreted in this work using the random pore model (RPM) proposed by Bhatia $^{36}$ and recently adapted to the carbonation reaction in $\mathrm{CaL}$ systems $^{37,38}$. This model has also been previously applied to freshly calcined limestones to study the diffusion and kinetic resistances involved in the sulfation process ${ }^{20}$. The RPM model has a 
general expression which is valid for solid-gas reactions and which is also applicable to porous systems with product layer resistance. Thus:

$$
\frac{d X}{d t}=\frac{k_{s} S C \sqrt{1-\psi \ln (1-X)}}{(1-\varepsilon)\left[1+\frac{\beta Z}{\psi}(\sqrt{1-\psi \ln (1-X)}-1)\right]}
$$

where:

$$
\beta=\frac{2 k_{s} a \rho(1-\varepsilon)}{b M_{C a O} D}
$$

and $\mathrm{k}_{\mathrm{s}}$ is the rate constant for the surface reaction, $\mathrm{S}$ is the reaction surface area per unit of volume, $\varepsilon$ is the porosity of the particles, $\mathrm{D}$ is the effective product layer diffusivity and $\mathrm{C}$ is the $\mathrm{SO}_{2}$ concentration. In Eq. $2, \Psi$ is a structural parameter that takes into account the internal particle pore structure which can be calculated as:

$$
\psi=\frac{4 \pi L(1-\varepsilon)}{S^{2}}
$$

where $\mathrm{L}$ is the initial pore length in the porous system per unit of volume, $\mathrm{S}$ is the initial surface area per unit of volume and $\varepsilon$ is the porosity. For a chemically controlled reaction, the general rate expression from Eq. 1 can be simplified and integrated to yield the following equation [36]:

$$
\frac{1}{\psi}[\sqrt{1-\psi \ln (1-\mathrm{X})}-1]=\frac{\mathrm{k}_{\mathrm{s}} \mathrm{SCt}}{2(1-\varepsilon)}
$$

On the other hand, when chemical kinetics and diffusion through the product layer are controlling the overall reaction rate, Eq. 1 can be integrated to the following equation:

$$
\frac{1}{\psi}[\sqrt{1-\psi \ln (1-X)}-1]=\frac{S}{(1-\varepsilon)} \sqrt{\frac{D M_{C a O} C t}{2 \rho_{C a O} Z}}
$$

Textural parameters used as inputs in the RPM model (S, L and $\varepsilon$ ) can be determined from experimental measurements ${ }^{20}$. In the case of cycled $\mathrm{CaO}$, since the textural properties $\left(\mathrm{S}_{\mathrm{N}}, \mathrm{L}_{\mathrm{N}}\right)$ 
change during cycling, their values for each cycle need to be known before the model can be applied. To avoid the need for experimental measurement of these parameters and in the absence of a detailed sintering model able to estimate the pore size distribution during cycling, we adopted a similar methodology to that proposed by Grasa et al. ${ }^{37}$ applying the random pore model to the carbonation reaction of the cycled particles. Assuming that $\mathrm{CaCO}_{3}$ forms a fairly constant layer at the end of the fast carbonation period $^{32}$ and the total pore volume remains constant with the number of cycles, these authors proposed to determine $S_{N}$ and $L_{N}$ for each cycle, from the initial values $\left(\mathrm{S}_{0}\right.$ and $\left.\mathrm{L}_{0}\right)$ and the maximum $\mathrm{CO}_{2}$ carrying capacity of the sorbent $\left(\mathrm{X}_{\mathrm{N}}\right)$ as follows:

$$
\begin{aligned}
& S_{N}=S_{0} X_{N} \\
& L_{N}=L_{0} X_{N} \frac{r p_{0}}{r p_{N}}
\end{aligned}
$$

where $\mathrm{S}_{0}$ and $\mathrm{L}_{0}$ are the values corresponding to the initial fresh calcined limestones, and $\mathrm{rp}$ is the pore radius ( $\mathrm{rp}_{0}$ initial value, $\mathrm{rp}_{\mathrm{N}}$ after $\mathrm{N}$ cycles). The maximum carrying capacity $\left(\mathrm{X}_{\mathrm{N}}\right)$ in each cycle can be calculated using the following equation proposed by Grasa et al. ${ }^{39}$ :

$$
X_{N}=\left(\frac{1}{\frac{1}{\left(1-X_{r}\right)}+k N}+X_{r}\right)
$$

where $\mathrm{k}$ is the deactivation constant, $\mathrm{X}_{\mathrm{r}}$ is the residual conversion after an infinite number of cycles and $\mathrm{N}$ is the number of cycles. Values of $\mathrm{k}=0.52$ and $\mathrm{X}_{\mathrm{r}}=0.075$ have been proven to be valid for a wide range of sorbents and carbonation conditions and have been used in this work. The values calculated for $\mathrm{X}_{\mathrm{N}}$ by means Eq. 8 were compared with the experimental $\mathrm{CO}_{2}$ carrying capacities obtained during TGA cycling and a good agreement was found. We estimated the initial surface $\left(\mathrm{S}_{0}\right)$ area of the fresh calcined limestones from the maximum $\mathrm{CO}_{2}$ carrying 
capacity of the sorbent in the first cycle assuming the $\mathrm{CaCO}_{3}$ layer thickness at the end of the fast reaction regimen to be $49 \mathrm{~nm}^{32}$. This yields an initial value of $30 * 10^{6} \mathrm{~m}^{2} / \mathrm{m}^{3}$ assuming an initial $\mathrm{CO}_{2}$ carrying capacity of 0.7 (using $\mathrm{N}=1$ in Eq. 8). The initial values of pore length $\left(\mathrm{L}_{0}\right)$ and porosity $(\varepsilon)$ used for the three limestones were $4.16^{*} 10^{14} \mathrm{~m} / \mathrm{m}^{3}$ and 0.46 , respectively. These values were taken from a study of Grasa et al. ${ }^{37}$ in which calcined Imeco limestone was characterized by mercury porosimetry.

Once the evolution of the surface area $\left(\mathrm{S}_{\mathrm{N}}\right)$ and $\Psi_{\mathrm{N}}$ were calculated with the number of cycles, the reaction parameters, $\mathrm{k}_{\mathrm{s}}$ and D, were determined by fitting Eqs. 4 and 5 to the experimental data. Figure 4 shows an example of the fitting of these equations to the experimental data obtained during the sulfation of Enguera limestone after 20 cycles of calcination/carbonation. Figures $4 \mathrm{a}$ and $4 \mathrm{~b}$ represent the left hand side of Eqs. 4 and 5 against time and time $\mathrm{e}^{1 / 2}$, respectively. From the slopes of the straight lines, $\mathrm{k}_{\mathrm{s}}$ and $\mathrm{D}$ can be calculated. As can be seen from these figures, there is a clear threshold between the chemical and the diffusion controlled regime that can be easily identified for $\mathrm{f}(\Psi) \sim 0.5$ which corresponds approximately to $\mathrm{X}_{\mathrm{CaSO} 4}=0.10$. A similar marked threshold was observed for the other samples studied. This indicates that under these experimental conditions and with this particle size, the overall reaction rate is initially controlled by the chemical reaction rate that takes place over the entire surface of the sorbent. However, as the reaction proceeds, the surface is covered by a layer of $\mathrm{CaSO}_{4}$ and diffusion through the product layer becomes the limiting step. No pore diffusion effects were detected in the experiments or used in the model. 
Figure 4. Fitting of Eq. 4 (a) and 5 (b) to the experimental data obtained for the Enguera limestone at $\mathrm{N}=20\left(\mathrm{~T}=650^{\circ} \mathrm{C}, \mathrm{SO}_{2}\right.$ concentration $\left.=500 \mathrm{ppmv}\right)$.

Before discussing the values of $\mathrm{k}_{\mathrm{s}}$ and $\mathrm{D}$ (shown in Table 2), it may be useful to test the suitability of this model for describing the evolution of $\mathrm{X}_{\mathrm{CaSO} 4}$ with time. $\mathrm{CaO}$ conversion to $\mathrm{CaSO}_{4}$ with reaction time can be calculated using the following equations which can be derived from Eqs. 4-5:

a) for the chemically controlled regime:

$$
X=1-\exp \left(\frac{1-\left(\frac{\tau}{2} \psi_{N}+1\right)^{2}}{\psi_{N}}\right)
$$

b) for the diffusion controlled regime:

$$
X=1-\exp \left(\frac{1}{\psi_{N}}-\frac{\left[\sqrt{1+\beta Z \tau}-\left(1-\frac{\beta Z}{\psi_{N}}\right)\right]^{2} \psi_{N}}{(\beta Z)^{2}}\right)
$$

where

$\tau=\frac{k_{s} C S_{N} t}{(1-\varepsilon)}$

Figure 5 compares the experimental values with those calculated for Compostilla limestone for different numbers of cycles. In this figure, the transition between chemically and diffusion controlled regime has been obtained from the experimental results (typically around 120-180 s). Moreover, $\mathrm{X}_{\mathrm{CaSO} 4}$ has been calculated using the $\mathrm{k}_{\mathrm{s}}$ and $\mathrm{D}$ values derived for each cycle. As can be seen in the figure, the model only predicts satisfactorily the $\mathrm{CaO}$ conversion up to a value of $\sim$ 
0.10 in the case of the fresh calcined limestone $(\mathrm{N}=1)$, which corresponds to a reaction time of around 4 minutes. From this point, the calculated values clearly overpredict the experimental ones. In contrast, for the sorbent obtained after 10 calcination/carbonation cycles, the model is able to calculate the sorbent conversion up to values of $\mathrm{X}_{\mathrm{CaSO} 4}=0.2$ which corresponds to a reaction time of approximately 10 minutes. In the case of the sorbent that has been cycled 20 and 50 times, the $\mathrm{X}_{\mathrm{CaSO} 4}$ values calculated with the RPM model are in close agreement with the experimental ones over the entire reaction period.

The fact that the model correctly predicts the evolution of the sulfation conversion of the sorbent obtained after many carbonation-calcination cycles is a strong validation of the RPM model when applied to our results. It shows that the product layer of $\mathrm{CaSO}_{4}$ is able to grow around the whole particle without experiencing any geometrical restrictions. The homogeneous model is not valid for particles derived from fresh calcined limestone because they undergo pore plugging as reaction proceeds. In the case of $\mathrm{N}=10$, the pore structure must be in an intermediate stage.

Figure 5. Comparison of experimental and calculated values of $\mathrm{X}_{\mathrm{CaSO} 4}$ for Compostilla limestone with different numbers of cycles ((a) first cycle, (b) higher cycles) (T=650 ${ }^{\circ} \mathrm{C}, \mathrm{SO}_{2}$ concentration $=500 \mathrm{ppmv}$ ) (calculated values-solid lines).

In a postcombustion Ca-looping system, most particles will have been cycling the system 10 s of times depending on the make up flow ratio of fresh limestone ${ }^{34}$. Therefore, the assumption that the sulfation reaction progresses homogeneously in the particles, as indicated by equations $1-8$, will serve as an adequate approximation for practical reactor modelling purposes. A good 
agreement between the calculated values for cycled particles was found for each limestone, indicating the intrinsic nature of the values of ks and D. In contrast, the best-fit values for the first cycle were clearly lower that the average values for all three limestones, especially in the case of the effective product layer diffusivity (D), which tends to be one order of magnitude lower. This can be explained by taking into account that the reaction surface in the particles has been calculated by means of Eqs. 6 and 8, which will tend to overestimate the reacting surface when small pores (that are prompt to $\mathrm{CaSO}_{4}$ plugging) are present. The average values of $\mathrm{k}_{\mathrm{s}}$ and D for each limestone are summarized in Table 2. These have been calculated using the values of ks and D calculated for each cycle, except those corresponding to the fresh calcined limestone $(\mathrm{N}=1)$.

Table 2. Calculated kinetic rate parameters $\left(\mathrm{k}_{\mathrm{s}}\right.$ and $\left.\mathrm{D}\right)$ for the different limestones at $650^{\circ} \mathrm{C}$.

The values presented in Table 2 are in agreement with those found by Bhatia ${ }^{20}$ for fresh calcined sorbents at temperatures of around $650{ }^{\circ} \mathrm{C}$. Table 2 also shows the sulphate conversion at which the transition between the chemical and diffusion controlled regime is experimentally observed. From the values of $\mathrm{X}_{\mathrm{CaSO} 4}$ and the surface area $\left(\mathrm{S}_{\mathrm{N}}\right)$, it is possible to estimate the thickness of the product layer (h) at which the reaction becomes diffusion controlled by means of the following equation:

$$
h=\frac{X_{\mathrm{CaSO}_{4}} \rho_{\mathrm{CaO}} V_{\mathrm{MCaSO}_{4}}}{S_{N} M_{\mathrm{CaO}}}
$$

The calculated values of $\mathrm{h}$ are shown in Table 2. An average $\mathrm{CaSO}_{4}$ layer thickness of $8.5 \mathrm{~nm}$ is obtained. This average value can be used to estimate the sulphate conversion that marks the transition between the kinetic and the diffusion controlled regimes. 
Although this work focussed on the carbonator reactor, where the operation temperature will be fairly constant at around $650{ }^{\circ} \mathrm{C}$, we attempted to determine the influence of the temperature on the kinetic rate parameters by means of the Arrhenius equation:

$$
\begin{aligned}
& k_{s}=k_{s 0} \exp \left(-E_{a k} / R T\right) \\
& D=D_{0} \exp \left(-E_{a D} / R T\right)
\end{aligned}
$$

For this purpose, we carried out tests at higher temperatures to determine $\mathrm{k}_{\mathrm{s}}$ and $\mathrm{D}$. However, diffusional resistances were observed during the tests at higher temperatures, which could not be avoided in our experimental set-up. To overcome this problem and to reduce the number of adjustable parameters, we determined the values of the pre-exponential factors, assuming an activation energy of $56 \mathrm{~kJ} / \mathrm{mol}$ and $120 \mathrm{~kJ} / \mathrm{mol}$ as calculated by Bhatia ${ }^{20}$ for $\mathrm{k}_{\mathrm{s}}$ and $\mathrm{D}$, respectively. The results obtained are shown in Table 3.

Table 3. Kinetic parameters of Eqs. 15 and 16 for the three limestones.

Figure 6 shows the experimental evolution of $\mathrm{X}_{\mathrm{CaSO} 4}$ with sulfation time together with those calculated using the average values of Table 2 and assuming a layer thickness of $8.5 \mathrm{~nm}$ for Enguera and Compostilla limestone with different numbers of cycles. As can be seen, there is reasonable agreement between the experimental and calculated values, confirming the suitability of the model for determining the sulfation rates of cycled sorbents. 
Figure 6. Comparison of experimental values of $\mathrm{X}_{\mathrm{CaSO} 4}$ of Enguera (a) and Compostilla (b) limestones for $\mathrm{N}=20$ and 50 with those calculated by means of the model and the average values shown in Table 2 (solid lines) $\left(\mathrm{T}=650^{\circ} \mathrm{C}, \mathrm{SO}_{2}\right.$ concentration $\left.=500 \mathrm{ppmv}\right)$.

When applying the RPM model to design Ca-looping systems, it will be found that for the typically low sulfation conversions of solids in these systems, the particles will react mainly under the chemical controlled regime. Therefore the sulfation rate can be calculated by using the simplified form of Eq. 1 for this regime together with the parameters reported in Table 3:

$$
\frac{d X}{d t}=\frac{k_{s} S C(1-X) \sqrt{1-\psi \ln (1-X)}}{(1-\varepsilon)}
$$

The high reaction rate achieved for $\mathrm{SO}_{2}$ capture under typical carbonator conditions in postcombustion Ca-looping systems, confirms that these reactors are suitable as $\mathrm{SO}_{2}$ absorbers and as high-temperature $\mathrm{CO}_{2}$ capture devices.

\section{CONCLUSIONS}

The random pore model has been applied to study the sulfation behaviour of cycled $\mathrm{CaO}$ particles at a temperature of $650^{\circ} \mathrm{C}$ (typical of carbonator reactors in Ca-looping $\mathrm{CO}_{2}$ capture systems). Under these conditions, the sulfation proceeds through an initial chemically controlled step followed by second period where chemical reaction and diffusion through the product layer are the controlling resistances. Sulfation has been found to be a first reaction order with respect to $\mathrm{SO}_{2}$ under the experimental conditions tested. The rate constants for surface reaction $\left(\mathrm{k}_{\mathrm{s}}\right)$ between $4.32 * 10^{9}$ and $5.63 * 10^{9} \mathrm{~m}^{4} / \mathrm{mol} \mathrm{s}$ were calculated at $650{ }^{\circ} \mathrm{C}$ for the three limestones used. The calculated values of effective product layer diffusivity (D) range from $2.43 * 10^{-12}$ to $4.88^{*} 10^{-}$ ${ }^{12} \mathrm{~m}^{2} / \mathrm{s}$. These values are in agreement with those found in the literature under similar conditions. 
The results obtained with RPM indicate that cycled sorbents do not undergo pore plugging due to the growth of a layer of $\mathrm{CaSO}_{4}$ (for reaction times of up to $20 \mathrm{~min}$ ). For low $\mathrm{CaO}$ conversion $\left(\mathrm{X}_{\mathrm{CaSO} 4}<0.05\right)$, sulfation is a chemically controlled reaction. The high sulfation rates measured with highly cycled (carbonation-calcination) particles seem to indicate that post combustion Calooping carbonator reactors will be effective reactors for capturing $\mathrm{SO}_{2}$ from flue gases.

\section{ACKNOWLEDGEMENTS}

This work is partially funded by the European Commission (FP7-CaOling project).

\section{NOTATION}

$\mathrm{a}, \mathrm{b} \quad$ stoichiometric coefficients for carbonation reaction

C concentration of $\mathrm{CO}_{2}, \mathrm{kmol} / \mathrm{m}^{3} ; \mathrm{b}$, bulk concentration; e, equilibrium

D effective product layer diffusivity, $\mathrm{m}^{2} / \mathrm{s}$

$\mathrm{D}_{0} \quad$ pre-exponential factor in Eq. $16, \mathrm{~m}^{2} / \mathrm{s}$

$\mathrm{E}_{\mathrm{ak}} \quad$ activation energy for the kinetic regime, $\mathrm{kJ} / \mathrm{mol}$

$\mathrm{E}_{\mathrm{aD}} \quad$ activation energy for the combined diffusion and kinetic regime, $\mathrm{kJ} / \mathrm{mol}$

$\mathrm{h}$ product layer thickness, $\mathrm{m}$

$\mathrm{k} \quad$ sorbent deactivation constant

$\mathrm{k}_{\mathrm{s}} \quad$ rate constant for surface reaction, $\mathrm{m}^{4} / \mathrm{mols}$

$\mathrm{k}_{\mathrm{s} 0} \quad$ pre-exponential factor in Eq. $15, \mathrm{~m}^{4} / \mathrm{mols}$

$\mathrm{L}$ total length of pore system, $\mathrm{m} / \mathrm{m}^{3}$

M molecular weight, $\mathrm{kg} / \mathrm{kmol}$

$\mathrm{N} \quad$ number of calcination/carbonation cycles

$\mathrm{rp}_{\mathrm{N}} \quad$ radius of the pore after $\mathrm{N}$ cycles $(\mathrm{m})$

$\mathrm{S}$ reaction surface per unit of volume, $\mathrm{m}^{2} / \mathrm{m}^{3}$

$\mathrm{t}$ reaction time, $\mathrm{s}$

$\mathrm{V}_{\mathrm{M}} \quad$ molar volume, $\mathrm{m}^{3} / \mathrm{kmol}$

$\mathrm{X}_{\mathrm{N}} \quad \mathrm{CaO}$ molar conversion to $\mathrm{CaCO}_{3}$ in each cycle

$\mathrm{X}_{\mathrm{CaSO} 4} \quad \mathrm{CaO}$ molar conversion to $\mathrm{CaSO}_{4}$

$\mathrm{X}_{\mathrm{r}} \quad$ residual $\mathrm{CaO}$ conversion

$\mathrm{Z}$ ratio volume fraction after and before reaction

\section{Greek letters}

$\beta \quad 2 \mathrm{k}_{\mathrm{s}}$ a $\rho(1-\varepsilon) / \mathrm{M}_{\mathrm{CaO}}$ b D S

$\varepsilon \quad$ porosity

$\rho \quad$ density, $\mathrm{kg} / \mathrm{m}^{3}$

$\psi \quad 4 \pi \mathrm{L}(1-\varepsilon) / \mathrm{S}^{2}$

$\tau \quad \mathrm{k}_{\mathrm{s}} \mathrm{C} \mathrm{St} /(1-\varepsilon)$ 


\section{REFERENCES}

1. Anthony EJ. Solid looping cycles: A new technology for coal conversion. Ind. Eng. Chem. Res. 2008; 47: 1747-1754.

2. Blamey J, Anthony EJ, Wang J, Fennel PS. The calcium looping cycle for large-scale $\mathrm{CO}_{2}$ capture. Progress in Energy and Combustion Science. 2010; 36: 260-279.

3. Shimizu T, Hirama T, Hosoda H, Kitano K, Inagaki M, Tejima K. A twin fluid-bed reactor for renoval of $\mathrm{CO}_{2}$ from combustion processes. Trans IChemE. 1999; 77: 62-68.

4. Romeo LM, Abanades JC, Escosa JM, Paño J, Jiménez A, Sánchez-Biezma A, Ballesteros JC. Oxyfuel carbonation/calcination cycle for low cost $\mathrm{CO}_{2}$ capture in existing power plants. Energy Conversion Management. 2008; 49: 2809-2814.

5. Romano M. Coal-fired power plant with calcium oxide carbonation for post-combustion $\mathrm{CO}_{2}$ capture. Energy Procedia. 2009; 1: 1099-1006.

6. Ströle J, Lasheras A, Galloy A, Epple B. Simulation of the carbonate looping process for postcombustion $\mathrm{CO}_{2}$ capture from a coal-fired power plant. Chem. Eng. Technol. 2009; 32: 435-442. 7. Yongping Y, Rongrong Z, Liqiang D, Kavosh M, Patchigolla K, Oakey J. Integration and evaluation of a power plant with a CaO-based $\mathrm{CO}_{2}$ capture system. International Journal of Greenhouse Gas Control. 2010; 4: 603-612.

8. Martínez I, Murillo R, Grasa G, Abanades JC. Integration of $\mathrm{Ca}$ looping system for $\mathrm{CO}_{2}$ capture in existing power plants. AIChE Journal. 2010; doi 10.1002/aic.12461.

9. Anthony EJ, Granatstein DL. Sulfation phenomena in fluidized bed combustion systems. Progress in Energy and Combustion Science. 2001; 27: 215-236. 
10. Li Y, Buchi S, Grace JR, Lim CJ. $\mathrm{SO}_{2}$ removal and $\mathrm{CO}_{2}$ capture by limestone resulting from calcination/sulfation/carbonation cycles. Energy \& Fuels. 2005; 19: 1927-1934.

11. Ryu HJ, Grace JR, Lim CJ. Simultaneous $\mathrm{CO}_{2} / \mathrm{SO}_{2}$ capture characteristics of three limestones in a fluidized-bed reactor. Energy \& Fuels. 2006; 20: 1621-1628.

12. Sun P, Grace JR, Lim CJ, Anthony EJ. Removal of $\mathrm{CO}_{2}$ by calcium-based sorbents in presence of $\mathrm{SO}_{2}$. Energy \& Fuels. 2007; 21: 163-170.

13. Grasa GS, Alonso M, Abanades JC. Sulfation in a carbonation/calcination loop to capture $\mathrm{CO}_{2}$. Ind. Eng. Chem. Res. 2008; 47: 1630-1635.

14. Manovic V, Anthony EJ. Sequential $\mathrm{SO}_{2} / \mathrm{CO}_{2}$ capture enhanced by steam reactivation of CaO-based sorbent. Fuel. 2008; 87: 1564-1573.

15. Manovic V, Anthony EJ, Loncarevic D. $\mathrm{SO}_{2}$ retention by CaO-based sorbent spent in $\mathrm{CO}_{2}$ looping cycles. Ind. Eng. Chem. Res. 2009; 48: 6617-6632.

16. Pacciani R, Müller CR, Davidson JF, Dennis JS, Hayhurst AN. Performance of novel synthetic Ca-based sorbent suitable for desulfurizing flue gases in a fluidized bed. Ind. Eng. Chem. Res. 2009; 48: 7016-7024.

17. Manovic M, Anthony EJ. Competition of sulphation and carbonation reactions during looping cycles for $\mathrm{CO}_{2}$ capture by CaO-based sorbents. J. Phys. Chem. A. 2010; 114: 3397-4002. 18. Abanades JC, Anthony EJ, Wang J, Oakey JE. Fluidized bed combustion systems integrating $\mathrm{CO}_{2}$ capture with $\mathrm{CaO}$. Env. Sci. Technol. 2005; 39: 2861-2866.

19. Georgakis C, Chang CW, Szekely J. A changing grain size model for gas-solid reactions. Chemical Engineering Science. 1979; 34: 1072-1075.

20. Bhatia SK, Perlmutter DD. The effect of pore structure on fluid-solid reactions: Application to the $\mathrm{SO}_{2}$-lime reaction. AIChE Journal. 1981; 27: 226-234. 
21. Borgwardt RH, Bruce KR. Effect of specific surface area on the reactivity of $\mathrm{CaO}$ with $\mathrm{SO}_{2}$. AIChE Journal. 1986; 32: 239-246.

22. Borgward RH, Bruce KR, Blake J. An investigation of product-layer diffusivity for $\mathrm{CaO}$ sulfation. Ind. Eng. Chem. Res. 1987; 26: 1993-1998.

23. Dennis JS, Hayhurst AN. Mechanism of the sulphation of calcined limestone particles in combustion gases. Chemical Engineering Science. 1990; 45: 1175-1187.

24. Hartman M, Coughlin RW. Reaction of sulfur dioxide with limestone and the grain model. AIChE·Journal. 1976; 22: 490-498.

25. Adánez J, García-Labiano F, Fierro V. Modelling for the high-temperature sulphation of calcium-based sorbents with cylindrical and plate-like geometries. Chemical Engineering Science. 2000; 55: 3665-3683.

26. Borgwardt $\mathrm{RH}$. Kinetics of the reaction of $\mathrm{SO}_{2}$ with calcined limestone. Environmental Science Technology. 1970; 4: 59-61.

27. Hartman M, Coughlin RW. Reaction of sulfur dioxide with limestone and the influence of pore structure. Ind. Eng. Chem. Process Des. Develop. 1974; 13: 248-253.

28. Pigford RL, Sliger G. Rate of diffusion-controlled reaction between gas and a porous solid sphere. Reaction of $\mathrm{SO}_{2}$ with $\mathrm{CaCO}_{3}$. Ind. Eng. Chem. Process Des. Develop. 1973; 12: 85-91. 29. Adánez J, Gayán P, García-Labiano F. Comparison of mechanistic models for the sulfation reaction in a broad range of particle sized of sorbents. Ind. Eng. Chem. Res. 1996; 35: 21902197.

30. Curran GP, Fink CE, Gorin E. $\mathrm{CO}_{2}$ acceptor gasification process. Studies of acceptor properties. Adv. Chem. Ser. 1967; 69: 141-161. 
31. Barker R. Reversibility of the reaction $\mathrm{CaCO}_{3}=\mathrm{CaO}+\mathrm{CO}_{2}$. J. Appl. Chem. Biotechnol. $1973 ; 23: 733-742$.

32. Alvarez D, Abanades JC. Determination of the critical product layer thickness in the reaction of $\mathrm{CaO}$ with $\mathrm{CO}_{2}$. Ind. Eng. Chem. Res. 2005; 44: 5608-5615.

33. González B, Grasa GS, Alonso M, Abanades JC. Modeling of the Deactivation in a Carbonate loop at high temperatures calcination. Ind. Eng. Chem. Res. 2008; 45: 9256-9262.

34. Abanades JC. The maximum capture efficiency of $\mathrm{CO}_{2}$ using a carbonation/calcination cycle of $\mathrm{CaO} / \mathrm{CaCO}_{3}$. Chemical Engineering Journal. 2002; 60: 303-306.

35. Abanades JC, Álvarez D. Conversion limits in the reaction of $\mathrm{CO}_{2}$ with lime. Energy \& Fuels. 2003; 17: 308-315.

36. Bhatia SK, Perlmutter DD. A random pore model for fluid-solid reactions: I. Isothermal, kinetic control. AIChE Journal. 1980; 26: 379-386.

37. Grasa G, Murillo R, Alonso M, Abanades JC. Application of the random pore model to the carbonation cyclic reaction. AIChE Journal. 2009; 55: 1246-1255.

38. Arias B, Abanades JC, Grasa GS. An analysis of the effect of carbonation conditions on $\mathrm{CaO}$ deactivation curves. Chemical Engineering Journal, 2011; 167: 255-261.

39. Grasa GS, Abanades JC. $\mathrm{CO}_{2}$ capture capacity of $\mathrm{CaO}$ in long series of carbonation/calcination cycles. Ind. Eng. Chem. Res. 2006; 45: 8846-8851. 

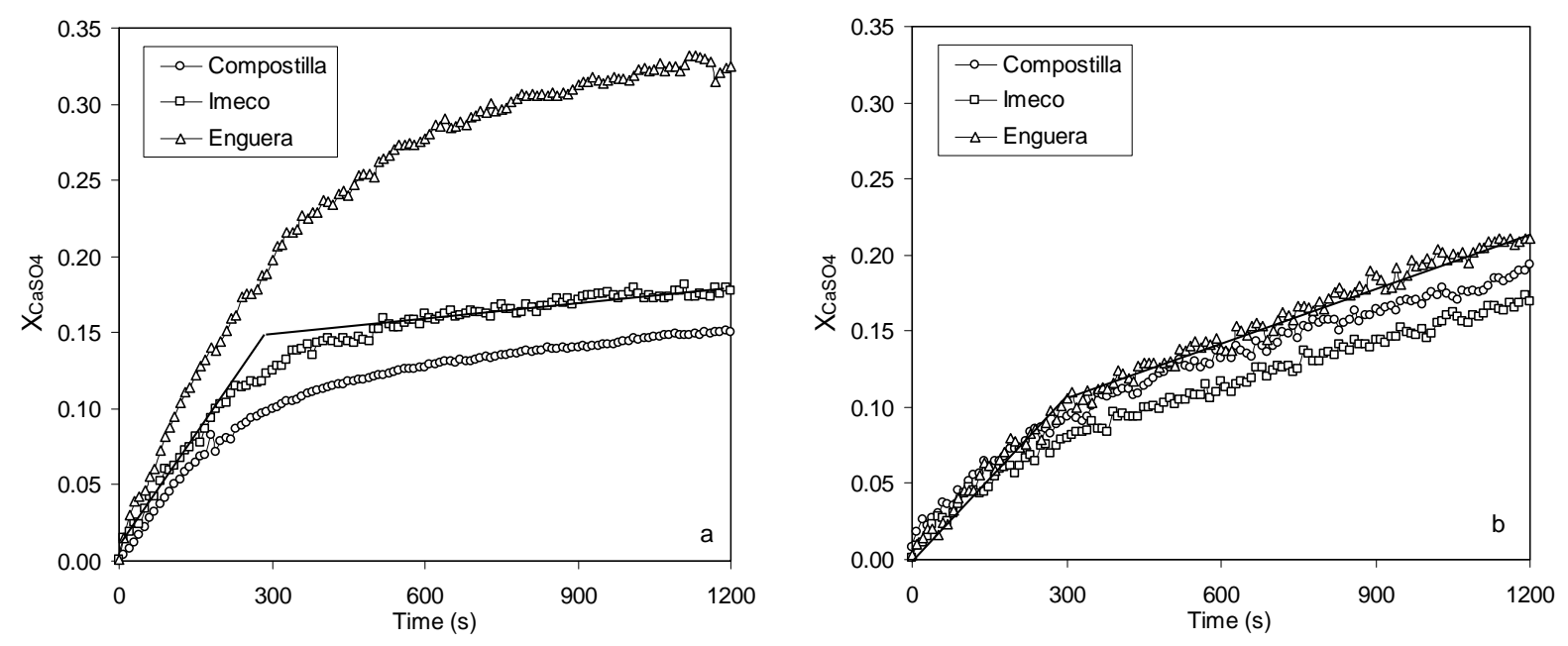

Figure 1. $\mathrm{X}_{\mathrm{CaSO} 4}$ vs time for limestones used in this work after the first calcination (a) and 50 calcination/carbonation cycles (b) $\left(\mathrm{T}=650^{\circ} \mathrm{C}, \mathrm{SO}_{2}\right.$ concentration $\left.=500 \mathrm{ppmv}\right)$. 


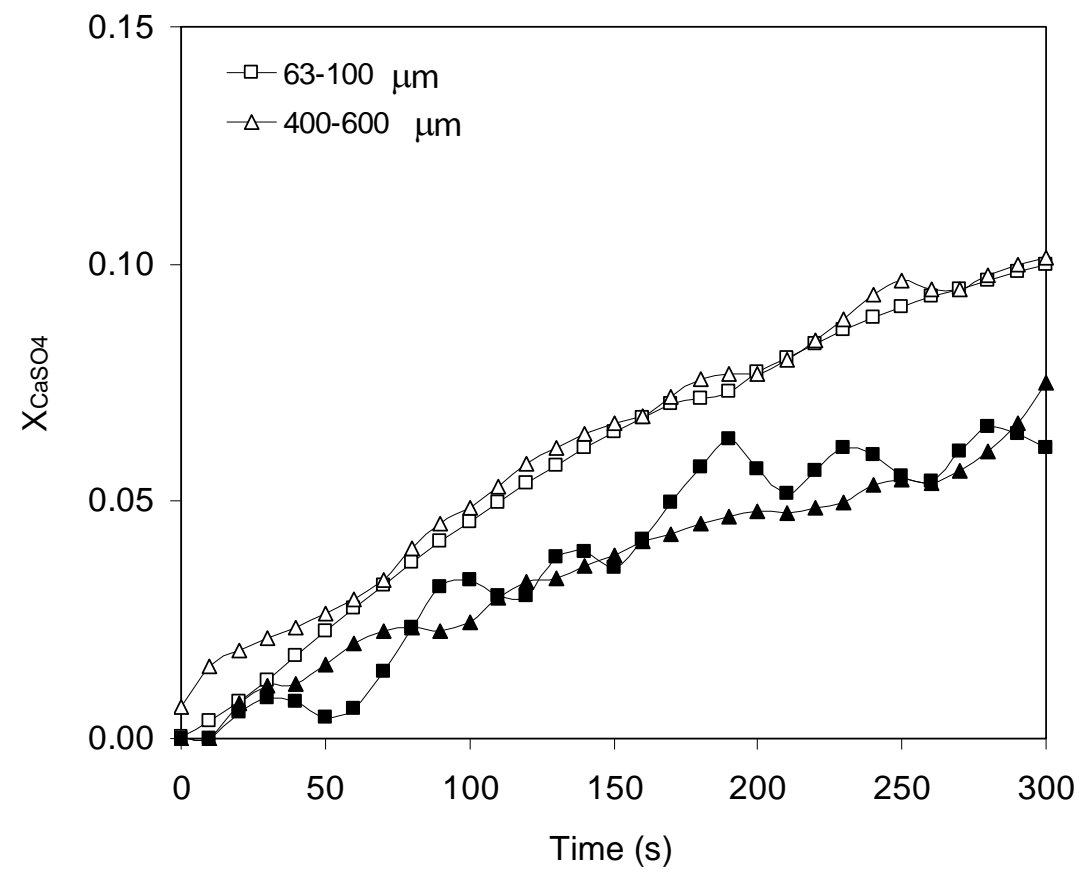

Figure 2. Effect of the particle size on the sulfation of $\mathrm{CaO}$ after the first calcination (empty symbols) and 20 calcination/carbonation cycles (filled symbols) $\left(\mathrm{T}=650 \quad{ }^{\circ} \mathrm{C}, \quad \mathrm{SO}_{2}\right.$ concentration $=500 \mathrm{ppmv})$. 

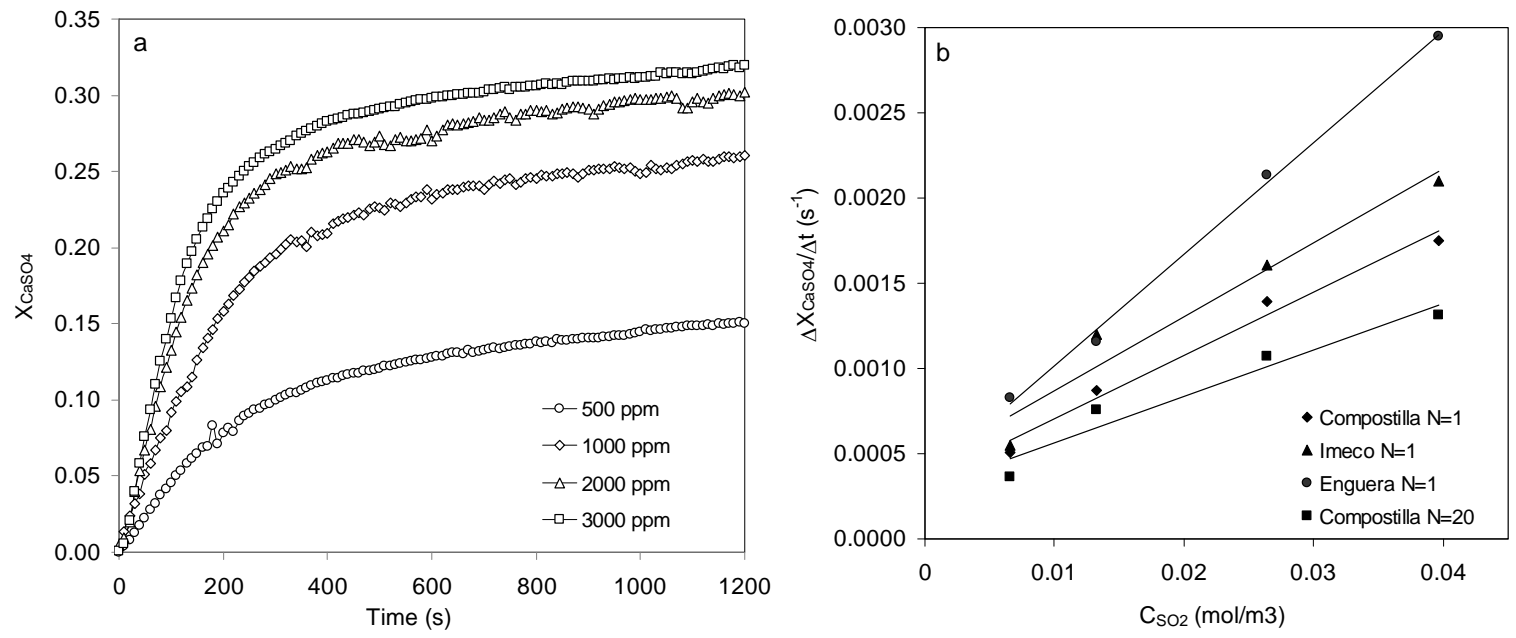

Figure 3. Effect of $\mathrm{SO}_{2}$ concentration on $\mathrm{XCaSO}_{4}$ for the fresh calcined Compostilla limestone $(\mathrm{N}=1)\left(\mathrm{T}=650{ }^{\circ} \mathrm{C}\right)(\mathrm{a})$ and the maximum reaction rate $\mathrm{vs} \mathrm{SO}_{2}$ concentration (b). 

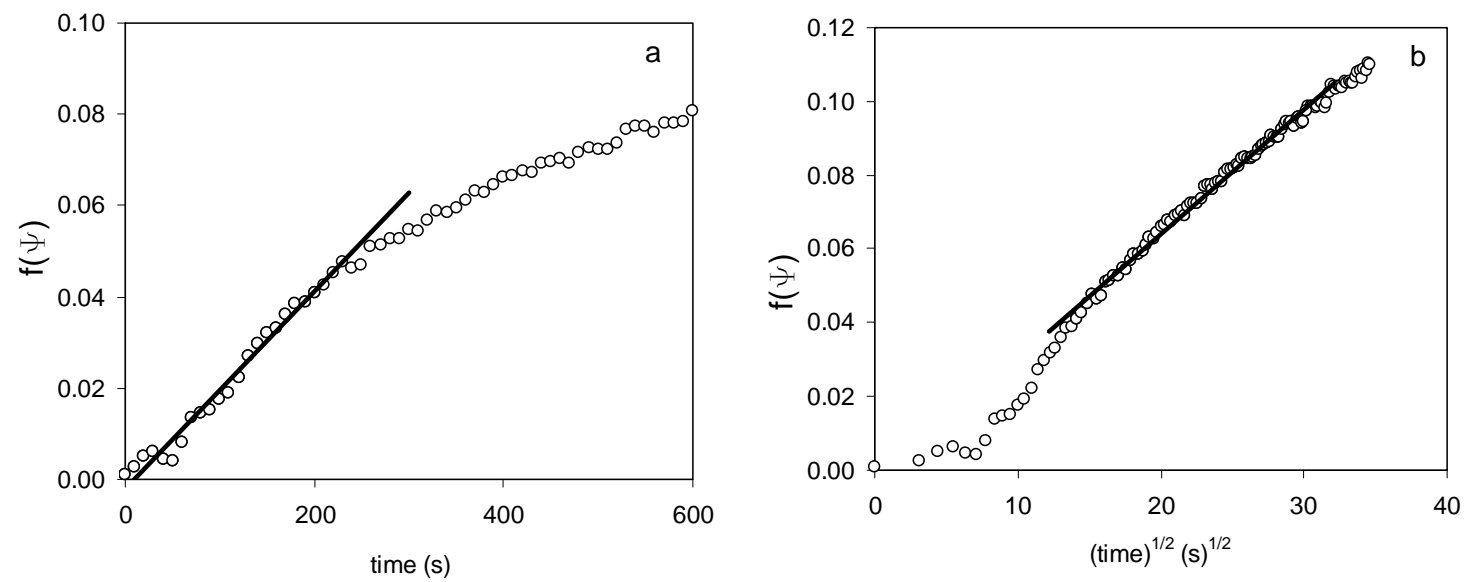

Figure 4. Fitting of Eq. 4 (a) and 5 (b) to the experimental data obtained for the Enguera limestone at $\mathrm{N}=20\left(\mathrm{~T}=650^{\circ} \mathrm{C}, \mathrm{C}_{\mathrm{SO} 2}=500 \mathrm{ppmv}\right)$. 

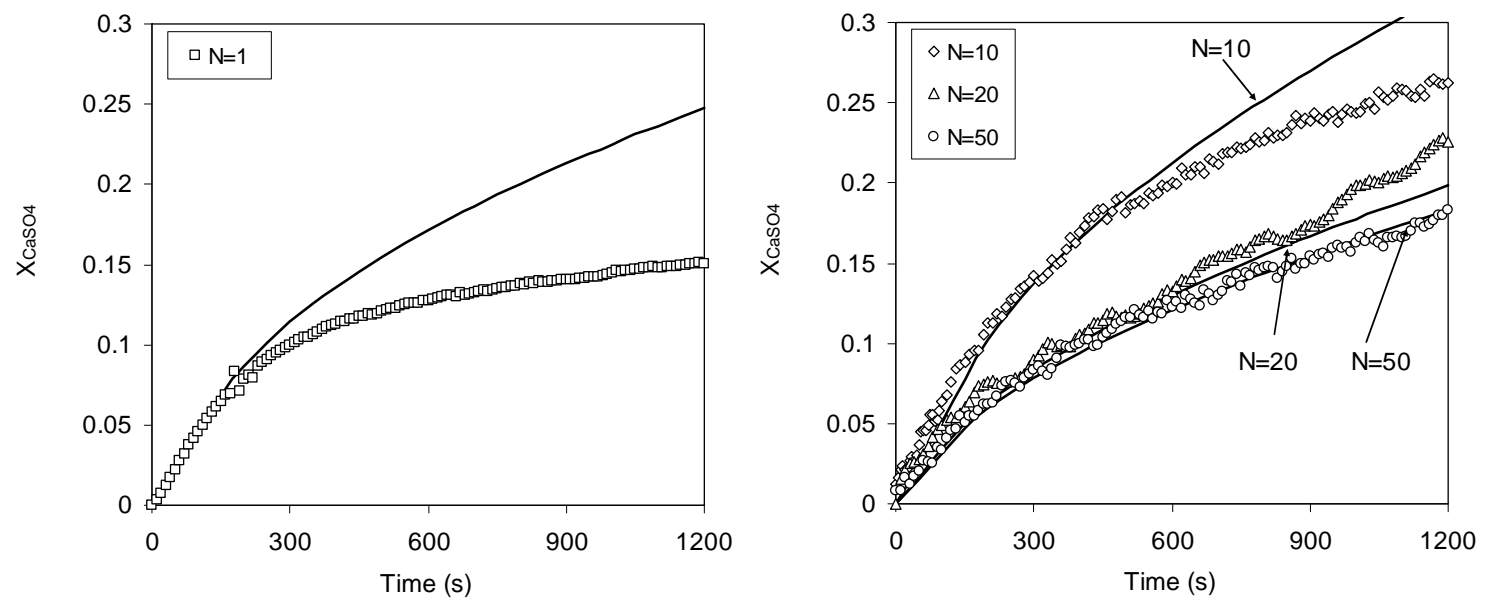

Figure 5. Comparison of experimental and calculated values of $\mathrm{XCaSO}_{4}$ for $\mathrm{Compostilla}$ limestone with different numbers of cycles $\left(\mathrm{T}=650^{\circ} \mathrm{C}, \mathrm{C}_{\mathrm{SO} 2}=500 \mathrm{ppmv}\right)$ (calculated values-solid lines). 

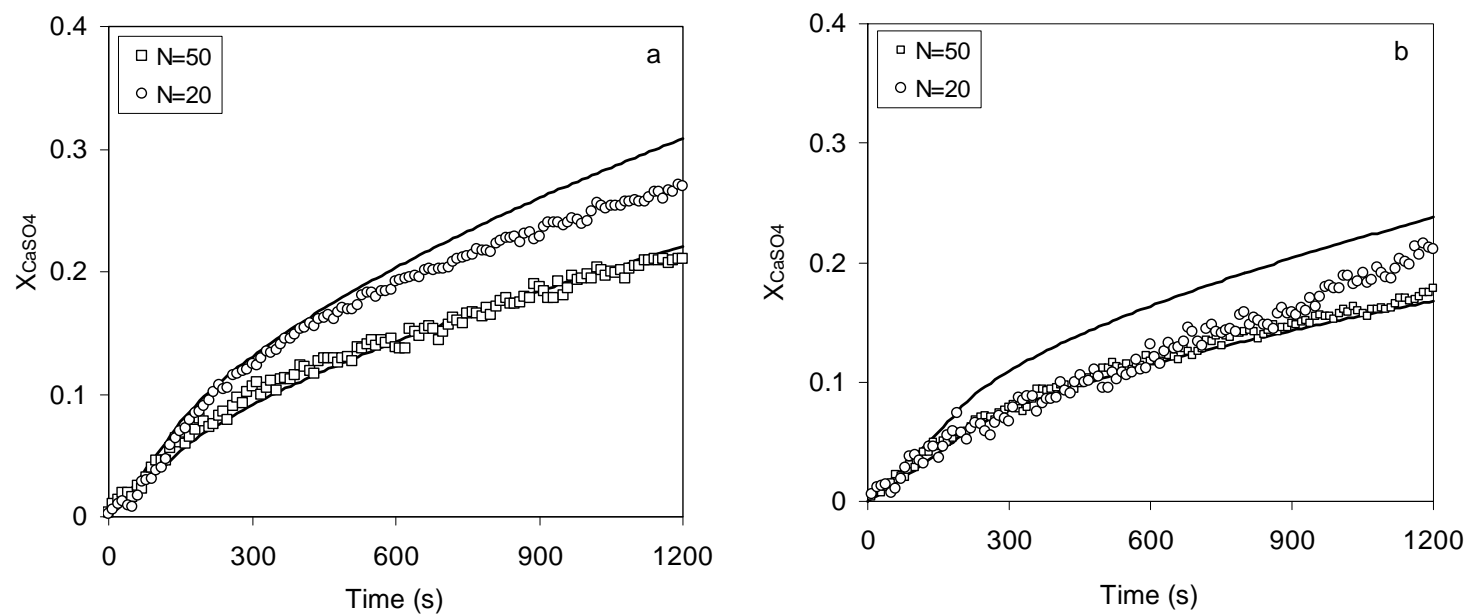

Figure 6. Comparison of experimental values of $\mathrm{XCaSO}_{4}$ of Enguera and Compostilla limestones for $\mathrm{N}=20$ and 50 with those calculated by means of the model and the average values shown in Table 2 (solid lines) $\left(\mathrm{T}=650^{\circ} \mathrm{C}, \mathrm{C}_{\mathrm{SO} 2}=500 \mathrm{ppmv}\right)$. 